\title{
Growth of anodic Aluminum Oxide using titanium as cathode - a review
}

\author{
Putu Hadi Setyarini ${ }^{1,{ }^{*}}$, Femiana Gapsari ${ }^{1}$ and Purnomo ${ }^{2}$ \\ ${ }^{1}$ Mechanical Engineering Department, Brawijaya University, 65145 Malang, Indonesia \\ ${ }^{2}$ Mechanical Engineering Department, Universitas Muhammadiyah Semarang, 50273 Semarang, \\ Indonesia
}

\begin{abstract}
Aluminum is a material with a variety of uses in various fields because this material is easy to obtain, can be made in various ways and has good corrosion resistance. Now this material begins to be studied and applied to the realm of biomaterials, with the use of the membrane of the aluminum oxide layer on the body of living things began to be applied. In this paper further elaborated on the use of titanium alloys as cathodes in the aluminum anodizing process. Deep discussion is emphasized on the growth process of the oxide layer that occurs during the anodizing process, where the oxide layer consists of a barrier layer and a pore layer. During the process, not only does the oxide layer grow with time but also the appearance of voids in the pore lining wall. In the final result, it was found that titanium was able to penetrate the oxide layer formed during the anodizing process. As for future applications, it is expected that the anodizing material is expected to be an alternative material in the field of biomaterial replacement
\end{abstract}

\section{Introduction}

Aluminum is widely used in many applications, such as in the automotive, marine, aerospace and other applications. Aluminum surfaces often experience contact with open surfaces [1]. This will cause a tendency for corrosion. In atmospheric conditions, aluminum becomes rapidly coated with an oxide layer $2-3 \mathrm{~cm}$ thick. This naturally formed aluminum oxide prevents the metal surface from further oxidation but the condition is not stable [2].

Anodizing is one of the electrochemical processes performed to produce a much thicker layer of oxide than a naturally occurring oxide layer, which undergoes improved physical and chemical properties [3-6]. There are two types of oxide layers that form on the aluminum surface after anodizing process [7-10]. The first layer is a barrier layer that is thin, hard, wear resistant and behaves as an electrical insulator. The second is a thicker pore layer and is often referred to as anodic aluminum oxide layer (AAO). Many improved mechanical properties such as excellent hardness, increased corrosion resistance and abrasion can be obtained by anodizing aluminum in the acid electrolyte solution. In

\footnotetext{
*Corresponding author: putu_hadi@ub.ac.id
} 
addition, due to its high porosity, the oxide film layer formed on the metal is very well used in electroplating, painting, and semi-permanent decoration coloring [11].

The successful application of alumina as a biomaterial began in the early 1970s [12]. Membranes formed on the oxide layer also begin to be applied to the medical world where one of them is the use of anodic aluminum oxide membrane (AAO) for drug delivery and biomaterial application [13]. In addition the AAO membrane was also successfully used as a template to control the growth of synthetic hydroxiapatite [14]. The use of AAO as a biomaterial still has deficiencies when compared to organs, such as the absence of complex responses such as organs in general [15]. Biomaterial have only a single response. In addition, there is also a tissue response after the installation of biomaterial in response to toxins and foreign responses to the body. This toxin response is attempted to be minimized by the use of titanium as the cathode in the AAO formation process because titanium is osseointegration, ie the ability to attach to surrounding tissue. In addition, this material is also able to interact with living cells or tissues without causing toxin reactions or trigger an immune reaction when used and able to withstand mechanical load (biomechanical) is very good [16].

\section{The Formation of the Oxide Layer}

Anodizing is a process engineering to improve the material surface oxide film layer that has been formed naturally by using an electrochemical process. This process will produce a new layer that consists of a porous outer layer called pore layer and an inner layer that is dense, known as barrier layer [9].

During the process of the formation of an aluminum alloy oxide layer, a layer of film grow along with the formation of thermal oxidation which affects the solubility of the coating film by the electrolyte solution. The growth of the film layer will compete with the growth speed and decay rate of the film layer [17].

The process of growth of the oxide layer of aluminum oxide in the electrolyte can be expressed by the following reaction:

and

$$
2 \mathrm{Al}^{3+}+3 \mathrm{H}_{2} \mathrm{O} \rightarrow \mathrm{Al}_{2} \mathrm{O}_{3}+6 \mathrm{H}^{+}+6 \mathrm{e}^{-}
$$

$$
\begin{aligned}
& 2 \mathrm{Al}+6 \mathrm{OH}^{-} \rightarrow \mathrm{Al}_{2} \mathrm{O}_{3}+3 \mathrm{H}_{2} \mathrm{O}+3 \mathrm{e}^{-} \\
& 2 \mathrm{Al}+3 \mathrm{O}^{2-} \rightarrow \mathrm{Al}_{2} \mathrm{O}_{3}+6 \mathrm{e}^{-}
\end{aligned}
$$

$\mathrm{OH}^{-}$obtained in equation (2) is produced in the electrolyte solution used in the anodizing process of the compound of water with a simple separation, or by the decomposition reaction of water and dissolved oxygen through the following reaction:

$$
\begin{aligned}
& \mathrm{H}_{2} \mathrm{O}+2 \mathrm{e}^{-} \rightarrow 2 \mathrm{OH}^{-}+\mathrm{H}_{2} \\
& \mathrm{O}_{2}+2 \mathrm{H}_{2} \mathrm{O}+4 \mathrm{e}^{-} \rightarrow 4 \mathrm{OH}_{-}^{-}
\end{aligned}
$$

Meanwhile, the ion of $\mathrm{O}^{2-}$ in the equation (3) can be formed on the electrolyte / oxide surface of the $\mathrm{OH}$ ions from the simple reaction of the separation of the water compound and in the final process [17].

Meanwhile at the anode the reaction occurs:

$$
\mathrm{Al} \rightarrow \mathrm{Al}^{3+}+3 \mathrm{e}^{-}
$$

Changes in the form of oxygen at the metal / oxide interface are shown in the following reactions:

Or if not,

$$
\begin{aligned}
& 2 \mathrm{H}_{2} \mathrm{O} \rightarrow \mathrm{O}_{2}+4 \mathrm{H}_{+}+4 \mathrm{e}^{-} \\
& 4 \mathrm{OH}^{-} \rightarrow 2 \mathrm{H}_{2} \mathrm{O}+\mathrm{O}_{2}+4 \mathrm{e}^{-}
\end{aligned}
$$

$$
2 \mathrm{O}^{2-} \rightarrow \mathrm{O}_{2}+4 \mathrm{e}^{-}
$$

The formation of oxygen bubbles formed on the surface of the anode, as shown in equation (9) occurs in the area around the interface metal / oxide. This change in the form 
of oxygen is directly related to the formation of the pore layer as indicated by the AFM test results in Figure 1. This process will be more complicated if it is affected by the presence of anions from electrolytes which are susceptible to oxidation as shown by the reaction:

$$
\mathrm{PO}_{4}^{3-} \rightarrow \mathrm{P}_{2} \mathrm{O}_{8}{ }^{2-}+3 \mathrm{e}^{-}
$$

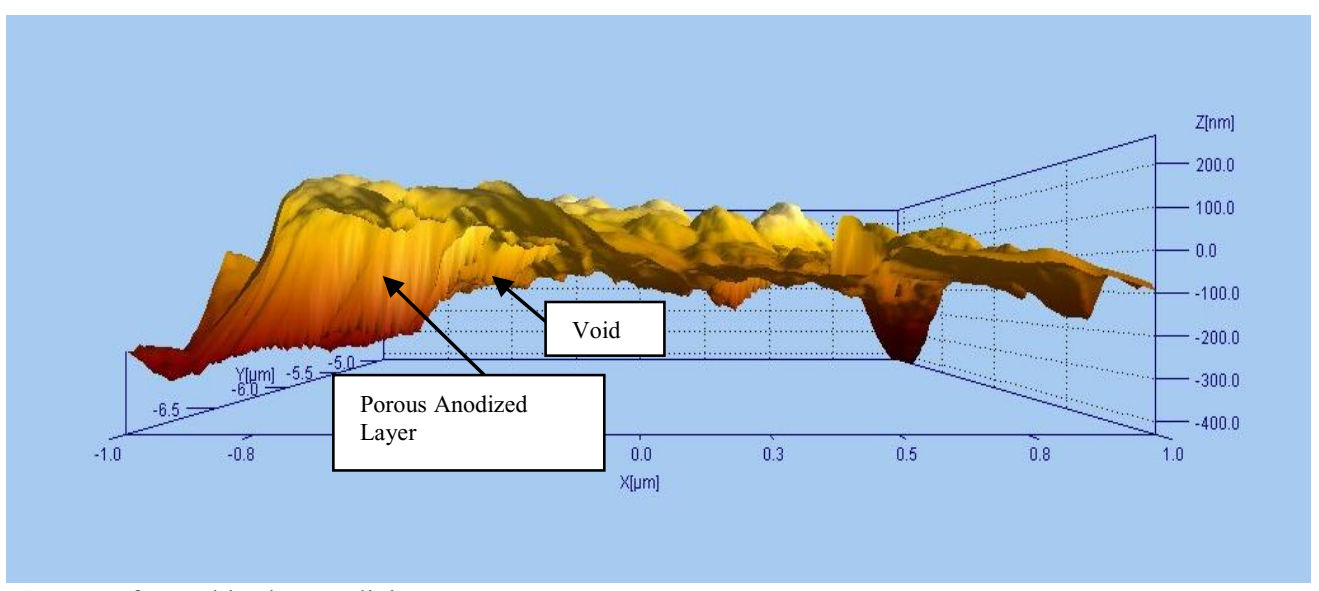

Fig. 1. Layer formed in the anodizing process

In addition to the layers formed during the anodizing process, voids on the pore wall also arise (Figure 1). Voids are small, small holes that form inside the hole as a result of the trapped air that occurs during the anodizing process. The process of the formation of voids starts to happen when the anodizing process began, voids arise at the interface of the oxide as a result of the release of $\mathrm{Al}^{3+}$ ions with the help of an electric field into the electrolyte. The condensation of the void begins at the defective area at the point of intersection of the grain boundary of the metal, and the void is formed. Void growing removed from the top of the protrusion when the interface shrinks into a bulk aluminum oxide during the formation of the oxide layer. After removing the void, void nucleus of the newly formed at the height of the bulk because aluminum is quickly saturated with a void. The new voids develop, they are released, and the whole process is repeated.

The growth of the oxide layer starts when the potential starts. $\mathrm{Al}_{2} \mathrm{O}_{3}$ layer is formed from the displacement of $\mathrm{Al}^{3+}$ and from the opposite direction $\mathrm{O}^{2-}$ to the metal interface / film layer / electrolyte solution, when oxidation heat begins to emerge as a result of the stress applied. When the film layer is formed, the displacement of the electrical charge will be blocked. Research showed that the layer formed is a layer of barrier [18]. During the oxidation process takes place, the surface of the barrier layer will be reduced by an electrolyte layer which begins with a small basin starting to form on the oxide / electrolyte interface and getting bigger until it forms a pore. These pores will continue to grow at a constant decay rate in the electric field. When the electrolyte solution penetrates the pores of the film layer, $\mathrm{Al}^{3+}$ and $\mathrm{O}^{2-}$ will move from the aluminum and electrolyte surfaces through the barrier layer. The film layer will be thicker and the oxidation heat will continue to increase.

The formation of the pore layer has a close relationship with the oxide decay process that occurs on the pore bed. On the other hand, oxide growth occurs primarily in the oxide / metal interface. The growth of the pore layer involves the transfer of oxygen containing $\mathrm{O}^{2-}$ or $\mathrm{OH}^{-}$ions from the electrolyte solution through the barrier layer, and the $\mathrm{Al}^{3+}$ ions will exit from the oxide layer. It states that only $\mathrm{Al}^{3+}$ ions take part in the oxide formation at the metal / oxide and oxide / electrolyte interfaces [19]. This is influenced by the voltage, where the voltage will affect the efficiency of current generated at the time of growth of the 
oxide layer. The formation of the oxide layer will continue at the oxide / electrolyte interface. A research stated that for the electrolyte phosphate, most of the $\mathrm{Al}^{3+}$ ions involved in the process of forming the oxide layer will reach the oxide / electrolyte interface [20]. This shows that for the growth of the oxide, about $40 \%$ of the oxide layer is formed at the oxide / electrolyte interface. This behavior is in accordance with a study conducted by which states the amount of $\mathrm{Al}^{3+}$ and $\mathrm{O}^{2-} / \mathrm{OH}^{-}$ion displacements observed for various electrolytes in the anodizing process ranged between 0.4 and 0.6 . The schematic representation of the basic processes involved in the growth of the oxide layer is shown in Figure 2.

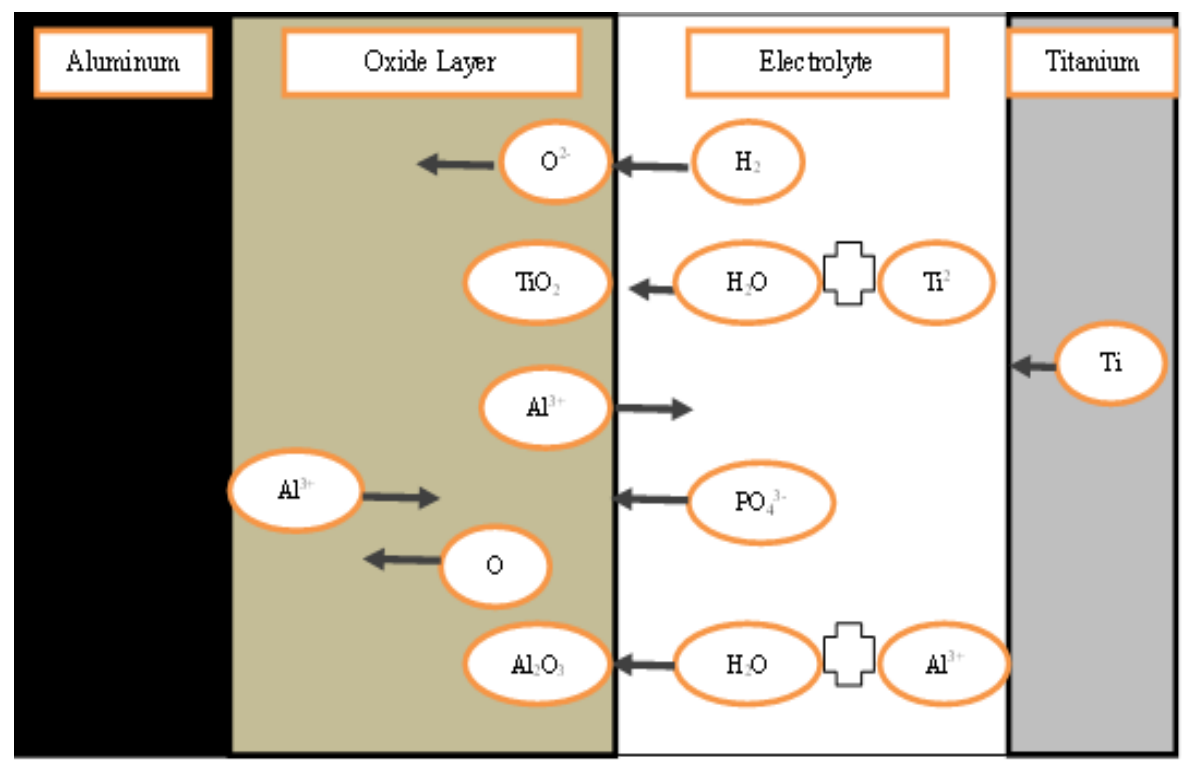

Fig. 2. The growth process of the oxide layer

Meanwhile, if titanium is used as a cathode in the anodizing process, the growth conditions of the oxide layer on aluminum begin simultaneously on the electrolyte / oxide and oxide / metal interfaces [21]. The Ti ions from the cathode will move directly into the solution and participate in the oxide coating formation process according to the reaction.

$$
\mathrm{Ti}^{2+}+2 \mathrm{e} \rightarrow \mathrm{Ti}
$$

At the time of growth of the pore layer occurring in a stable voltage state, the incorporation of titanium anions in the oxide layer occurs on the pore wall as a direct effect of ion transfer through electrolyte according to the reaction.

$$
\mathrm{Ti}+2 \mathrm{H}_{2} \mathrm{O} \rightarrow \mathrm{TiO}_{2}+2 \mathrm{H}_{2}
$$

There is also the possibility of the formation of two layers of the film during the process of anodizing aluminum with titanium cathode. The outer layer is rich with titanium, while the inner layer has decreased the deposit amount. In a study using aluminum and cerium, concluded that the film coating formed during the anodizing process has the ability to heal itself so that they can inhibit the decay rate of $\mathrm{Al}^{3+}$ ions in the electrolyte [22].

\section{Applications - A Preliminary Study}

As an initial step on the use of anodic coatings in the field of biomaterials and a research topic that is now emerging, several studies began using membrane oxide layers 
formed after anodizing processes on aluminum, such as cell interface substrate, cell culture substrate, tissue tissue substitution on skin and several other studies [23]. The ability of aluminum biocompatibility has been studied until now and there has been no rejection reaction from cultures tested on living things [12].

There are two significant advantages in using oxide film membranes for cell culture [24]. First able to control the size of the pore diameter, which can be adjusted over a wide range. Second, the transparent oxide layer membrane allows for routine inspection, to determine cell growth and morphology using optical microscopy.

While the use of titanium as a cathode is expected to increase the corrosion resistance and biocompatibility capability of the oxide layer formed after the anodizing process on aluminum [2]. In addition, this material is also able to interact with living cells or tissues without causing toxin reactions or trigger an immune reaction when used and able to withstand mechanical load (biomechanical) is very good [15].

One study has shown that titanium used as a cathode is able to penetrate to a certain depth in the anodizing aluminum oxide coating. In addition, it was also found that corrosion resistance also increased after aluminum experienced anodizing process with titanium cathodes [25-27].

\section{Conclusions}

Anodizing aluminum is an easy electrochemical process with a controlled process so that pore growth and mechanical properties can be tailored to the user's wishes. In this article, we examine the electrochemical process on the growth of the oxide layer on the aluminum process by using titanium cathodes as well as possible future applications in the biomaterials field. The application is expected to demonstrate the importance of anodic coating and this can only be obtained by continuous research so that it can find new applications.

\section{References}

1. W. Lee and S-J. Park. Chem. Rev. 114, 15 (2014)

2. P.H. Setyarini, R. Soenoko, A. Suprapto, Y. S. Irawan, J. Eng. App. Sci. 11, 22 (2017)

3. S. Mezlini, K. Elleuch, Ph. Kapsa, Surf. Coat. Tech. 2007, 201 (2007)

4. W. Bensalah, M. Feki, M. Wery, H F.Ayedi. J. Mat. Sci. Tech., 26 (2010).

5. M. Maejima, K. Saruwatari, K. Isawa, Met Finish, 10 (1998).

6. M. Guezmil, W. Bensalah, A. Khalladi, K. Elleuch, M. Depetris-Wery, H.F. Ayedi, Trans. Nonferrous Met. Soc. China 25 (2015)

7. V. Moutarlier, M.P. Gigandet, J. Pagetti, B. Normand, Surf. Coat. Tech. 161 (2002)

8. Y. Zuo, P.H. Zhao, J.M. Zhao. Surf. Coat. Tech., 166 (2003)

9. Y. Huang, H. Shih, H. Huang, J. Daugherty, S. Wub, S. Ramanathan, C. Chang, F. Mansfeld, Corr. Sci. 50, 12 (2008)

9. M. Saeedikhani, M. Javidi, A. Y. Trans. Nonferrous Met. Soc. China 23 (2013)

10. D.S. Al-Fattal, S.A.A. Al-Rabii, I.M. Al-Sudani. J. App. Sci. Res. 12, 11 (2016)

11. G.E.J. Poinern, N. Ali, D. Fawcett. Materials 4 (2011)

12. N. Ali, X. Duan, Z-T. Jiang, B.M. Goh, R. Lamb, A. Tadich, G.E.J Poinern, D. Fawcett, P. Chapman, P. Singh, Appl. Surf. Sci. 289 (2013)

13. Y. Zhang, L. Zhou, D. Li, N. Zue, X. Xu, J. Li. Chem. Phy. Lett. 376 (2003)

14. B.D. Ratner, Biomaterial Science, An Introduction to Materials in Medicine. Academic Press (1996) 
15. C. Massaro, P. Rotolo, F.D. Riccardis, E. Milella, J. Mat. In Medical. 13 (2002)

16. G.E. Thompson, Thin Sol. Films, 297 (1997)

17. A.T. Shawaqfeh and R.E. Baltus,. J. Membrane Sci., 157 (1999)

18. G. Patermarakis, J. Electroanal. Chem. 447 (1998)

19. G.E. Thompson, Y. Xu, P. Skeldon, K. Shimizu, S.H. Han, G.C. Wood, Philos. Mag. Part B 55, 6 (1987)

20. Y. Xu, G.E. Thompson, G.C .Wood, Trans. Inst. Met. Finish, 63 (1986)

21. P.H. Setyarini, R. Soenoko, A. Suprapto, Y. S. Irawan , App. Mech. Mat. 799-800 (2015)

22. F. Li, L. Zhang, R.M. Metzger, Chem. Mater. 10 (1998)

23. D. Bruggemann, J. Nano,. (2013)

24. A. Hoess, N. Teuscher, A. Thormann, H. Aurich, Heilmann, Acta Biomater. 3 (2007),

25. P.H. Setyarini, R. Soenoko, A. Suprapto, Y. S. Irawan, Int. Rev. Mech. Eng. 10, 3 (2016)

26. P.H. Setyarini, F. Gapsari, Purnomo, Int. J. Mech. Eng. Tech. 9, 6 (2018)

27. P.H. Setyarini, R. Soenoko, Y.S. Irawan, Purnomo, MM Sci. J., June (2018) 